\title{
First \& Second Law Analysis of Solar Air Heater
}

\author{
Vijay Mittal ${ }^{1, *}$ and Thakur Sanjay Kumar ${ }^{2}$ \\ ${ }^{1}$ Department of Mechanical Engineering, Gateway Institute of Engineering \& Technology, Sector-11, Sonipat, \\ Haryana, India \\ ${ }^{2}$ Department of Mechanical Engineering, Government Engineering College, Darbhanga (Bihar), India
}

\begin{abstract}
In this paper, thermodynamic analysis is performed for different cases of artificial roughness surface on the absorber plates of solar air heater duct. This analysis has been performed by using the correlations for heat transfer coefficient and friction factor developed experimentally for different type of roughness within the investigated range of operating and system parameters. The comparison has been made for different types of roughness on the basis of first law analysis (effective efficiency) and second law analysis (entropy, irreversibility distribution ratio and entropy generation number)
\end{abstract}

Keywords: Artificial Roughness, Solar Air Heater, Heat Transfer Coefficient, Friction Factor.

\section{INTRODUCTION}

Solar collectors are being used for thermal conversion to raise the temperature of fluid flowing through the collector. Conversion of solar radiations to thermal energy is mainly due to heat transfer coefficient between absorber plate and the fluid flowing in the collector. The most commonly used fluids in solar collectors are water and air. The solar air collector has an important place among solar thermal systems because it is widely used in many commercial applications such as the supply of hot air to school buildings and industrial drying etc. Its advantages are low cost, no freezing and no high pressure problems. However, the efficiency of solar air collectors is low because of the low Prandtl number of air [1]. There are several techniques of enhancement of heat transfer. In general, these techniques can be divided in to two groups: active and passive techniques. The active techniques require external forces, e.g. electric field, acoustic or surface vibration etc [2]. The passive techniques require fluid additives or special surface geometries. Artificial roughness on a surface is an effective technique to enhance the rate of heat transfer to fluid flow. Rough surface is used to increase the convective heat transfer by creating turbulence at the heat-transferring surface. However, energy for creating turbulence has to come from the fan or the blower and excessive turbulence means excessive power requirement. It is therefore, desirable that the turbulence must be created only very close to the surface i.e. in laminar sub layer only, where the heat exchange take place and the core of the flow is not unduly disturbed to avoid excessive losses.

${ }^{*}$ Address corresponding to this author at the Department of Mechanical Engineering, Gateway Institute of Engineering \& Technology, Sector-11, Sonipat, Haryana, India; Tel: (91) 9255526388;

E-mail:vmittal1231@rediffmail.com
The artificial roughened surface can be produced by several methods such as sand blasting, machining, casting, forming, welding ribs and by fixing thin circular wires along the surface. The surface roughness may be broadly classified as irregular roughness and regular roughness.

Several investigations [3-8] have been carried out to study the effect of artificial roughness on heat transfer and friction factor for two opposite roughness surfaces. Investigations of solar air heaters that form a system with only one roughened wall and three smooth walls have also been carried out by various researchers such as [9-21] etc.

The purpose of this paper is to perform the thermodynamic analysis of solar air heater by using different types of artificial roughness elements on the absorber plate in order to optimize the heat transfer and pressure drop. The thermodynamic analysis includes effective efficiency, entropy, irreversibility distribution ratio, entropy generation number based on the First and Second Law analysis. A comparison is made for different types of artificial roughness absorber plate and also compared with smooth plate. Each surface has optimum conditions for its own particular type of roughness.

\section{EXPERIMENTAL SET-UP}

The experimental set-up is an open loop flow system that has been designed and fabricated to conduct experimental investigation of heat transfer and fluid flow characteristics of a rectangular duct having $60^{\circ}$ inclined discrete wires roughness on the heated surface. It consists of a test duct along with entrance and exit sections, a suction blower and control valves, a calibrated orifice plate and various instruments are 
used for measurement of pressure and temperature drop. The blower sucks atmospheric air through the duct, having artificial roughness created by fixing $60^{\circ}$ inclined discrete ribs of circular cross section on the underside of the top plate. The flow through the duct can be controlled by means of control valves provided on the line. Mass flow rate of air was measured by means of an orifice meter on the suction side and connected to an inclined manometer. The test section consists of an $8 \mathrm{~mm}$ thick aluminium plate on its top, which is roughened at the flow passage side and the other three sides are smooth, made of wood. The upper walls of entry and exit sections of the duct are covered with smooth face $25 \mathrm{~mm}$ thick wood. The roughened plate is supplied with the heat energy by means of heater fixed on its upper side.

\section{MATHEMATICAL MODELING}

Let us consider the flow passage of cross section, $A$ and the heat transferring surface of width, $W$ shown schematically in Figure 1.

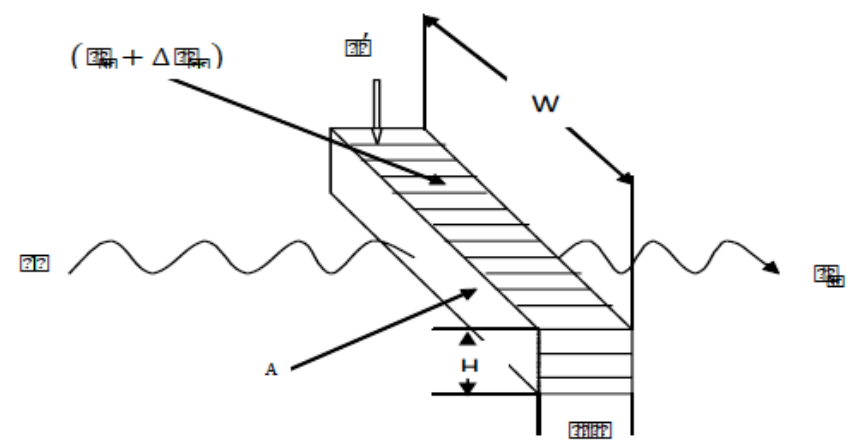

Figure 1: Heat Transferring Surface.

The bulk properties of the stream $\dot{m}$ are $T_{f}, \mathrm{P}, \mathrm{h}, \mathrm{s}$, $\rho$. In general, this heat transfer arrangement is characterized by a finite frictional pressure gradient $\frac{d p}{d x}>0$ and when heat is transferred to the stream at a rate $q(\mathrm{~W} / \mathrm{m})$, by a finite wall-bulk fluid temperature difference $\Delta T_{m}$. Considering on a slice of thickness $d x$ as a system, the rate of entropy generation for one inlet and one exit control volume is written as

$d s_{\text {gen }}^{\cdot}=\dot{m} d s+\frac{q^{\prime} d x}{\left(T_{f}+\Delta T_{m}\right)} \geq 0$

It is also known that if the process is reversible, $d s_{g e n}=0$ and if the process is irreversible, $d s_{g e n}>0$ is

The first law statement applied to the same system $\dot{m} d h=q^{\prime} d x$

Where $q^{\prime}=\frac{Q_{u 1}}{L}$

The second law statement applied to the same system is

$d h=T f \times d s+\frac{d p}{\rho}$

Substitution of $d s$ given by equation (1) and $d h$ given by equation (2) in equation (3), gives the entropy generation rate per unit duct length

$S_{g e n}=\frac{d \dot{s}_{g e n}}{d x}=\frac{q^{\prime} \Delta T_{m}}{T_{f}^{2}(1+2)}+\frac{\dot{m}}{\rho T_{f}}\left(-\frac{d P}{d x}\right)$

In solar air heater, the dimensionless temperature difference $\Gamma\left(=\frac{\Delta T_{m}}{T_{f}}\right)$ is negligible compared to unity. Taken this in to account, equation (4) reduces to

$$
\begin{aligned}
& S_{g e n}^{\cdot}=\frac{q^{\prime} \Delta T_{m}}{T_{f}^{2}}+\frac{\dot{m}}{\rho T_{f}}\left(-\frac{d P}{d x}\right) \\
& S_{g e n}^{\cdot}=S^{\prime}{ }_{\Delta T}+S^{\prime}{ }_{\Delta P}
\end{aligned}
$$

Where the first term, $S_{\Delta T}^{\prime}$, represents the irreversibility due to heat transfer across the wall-fluid temperature difference and the second term, $S_{\Delta P}^{\prime}$, is the irreversibility caused by fluid friction. In terms of the irreversibility distribution ratio, $\Psi=\frac{S^{\prime}{ }_{\Delta P}}{S^{\prime}{ }_{\Delta T}}$, equation (6) becomes.

$S_{g e n}^{\bullet}=S_{\Delta T}^{\prime}(1+\Psi)$

The relationship between heat transfer q' and wall bulk fluid temperature difference is expressed in terms of Stanton number such as:

$S t=\frac{q^{\prime} A / W \Delta T_{m}}{C_{p} \dot{m}}$

The fluid friction characteristics of a certain duct are usually reported in the form of friction factor correlations:

$f=\frac{\rho D A^{2}}{2 \dot{m}^{2}}\left(-\frac{d P}{d x}\right)$

Considering the case where the heat transfer rate, $q$ ' and mass flow rate, $\dot{m}$ are specified. The dependence of $S_{g e n}^{*}$ on Stanton number and friction factor is written as: 
$S_{g e n}^{\cdot}=\frac{q^{\prime 2} H}{T_{f}^{2} C_{p} m i s t}+f \frac{2 \dot{m}^{3}}{\rho^{2} T_{f} D A^{2}}$

$\Psi=2\left(\frac{f}{D S t}\right)\left(\frac{T_{f}}{\Delta T_{m}}\right)^{2}\left(\frac{\dot{m}^{2}}{\rho^{2} A W C_{p} T_{f}}\right)$

The impact of an augmentation technique on the irreversibility of a known solar air heater can be evaluated directly by calculating the entropy generation rate in the augmented passage, $S_{g e n, a}^{*}$ and comparing it with the entropy generation rate in the unaugmented passage, $S_{g e n, o}^{\cdot}$.

To quantize the thermodynamic impact of the augmentation technique [22], defined the augmentation entropy generation number

$N_{s, a}=\frac{S_{g e n, a}^{\bullet}}{S_{g e n, o}^{\bullet}}=\frac{\left(1+\Psi_{a}\right) s^{\prime}, a_{\Delta T}}{\left(1+\Psi_{o}\right) s^{\prime}, o_{\Delta T}}$

Suffix 'a' for augmented surface and 'o' for smooth surface.

Augmentation techniques with $N_{s, a}<1$ are thermodynamically advantageous since in addition to enhancing heat transfer they also reduce the degree of the irreversibility of the apparatus. Since the absorber plate roughness has a negligible impact on the flow cross-section area and hydraulic diameter. It is easy to show that when I, $\Delta \mathrm{T} / \mathrm{I}, T_{i}$ and $T_{o}$ are the same for smooth and augmented absorber plate of solar air heater, the entropy generation number can be written as

$$
N_{s, a}=\left(\frac{1+\Psi_{a}}{1+\Psi_{o}}\right) \times\left(\frac{S t_{a} \times R_{e a}}{S t_{o} \times R_{e o}}\right) \times\left(\frac{\Delta T_{m a}}{\Delta T_{m o}}\right)^{2}
$$

[23] defined the effective efficiency $\left(\eta_{\text {eff }}\right)$ of solar air heater as the ratio of the net energy gain to the energy available as insolation. The net energy gain is obtained by subtracting the pumping power from the energy gained by the air flowing through the collector. Thus, the effective efficiency represents the net gain per unit solar energy input. It is expressed as

$$
\eta_{e f f}=\frac{Q_{u 1}-p / c}{I A_{p}}
$$

Where $\mathrm{C}$ is conversion efficiency (mechanical power to thermal).

Considering that mechanical power is obtained from a typical thermal power plant. The value of $C$ is taken by considering typical values of various efficiencies as 0.2 [=thermal power plant efficiency (0.34) X transmission efficiency $(0.90) \times$ motor efficiency $(0.90)$ $X$ efficiency of the pump (0.75)]

\section{TYPES OF ARTIFICIAL ROUGHNESS USED IN SOLAR AIR HEATERS}

Different types of artificial roughness are used to conduct experiments by researchers in order to find out the effect of different roughened surfaces on heat transfer and friction factor for solar air heaters. Based on the experimental results, researchers developed the correlations for Nusselt number and friction factor. These correlations are being used to perform the first and second law analysis on solar air heater.

\section{METHOD OF COMPUTATION}

The thermal behavior of artificially roughened solar air heater is similar to that of usual flat plate conventional air heater; the usual procedures of calculating the absorbed irradiation and the heat losses can be used. The most important assumptions and simplifications which have been used are:

- $\quad$ steady-state conditions;

- heat conduction in flow direction neglected;

- edge effects neglected; constant air flow throughout the collector;

- $\quad$ sky treated as black body with a temperature equal to the ambient temperature.

Experimental investigations to determine Nusselt number and friction factor depending on the geometrical parameters have been done by the authors; these correlations are used in this paper for the numerical analysis.

The thermodynamic analysis of a solar air heater can also be predicted on the basis of detailed consideration of heat transfer processes in the system. This study is performed for different cases of artificial roughness surfaces on absorber plates of solar air heaters. Using the correlations for heat transfer coefficient and friction factor have been developed by researchers, and the performance parameters, namely overall heat transfer coefficient, heat removal factor and other relevant factors can then be evaluated. For this purpose a step-by-step procedure has to be followed. Various steps involved in the calculation have been explained below.

Area of absorber plate is given as:

$A p=W \times L$

Hydraulic diameter of duct as given below 
$D=\frac{2 W H}{(W+H)}$

$\Delta T=\frac{\Delta T}{I} \times I$

$T_{o}=T_{i}+\Delta T$

The mean bulk air temperature

$T_{f}=\frac{\left(T_{i}+T_{o}\right)}{2}$

The specific heat of air,

$C_{p}=1006\left(\frac{T_{f}}{293}\right)^{0.0155}$

The dynamic viscosity of air,

$\mu=1.81 \times 10^{-5}\left(\frac{T_{f}}{293}\right)^{0.735}$

The thermal conductivity of air,

$K=0.0257 \times\left(\frac{T_{f}}{293}\right)^{0.8}$

The density of air,

$\rho=\frac{97500}{287.045 \times T_{f}}$

The Prandtl number of air is given as:

$P_{r}=\frac{\mu \times C_{p}}{K}$

The bottom heat loss coefficient

$U_{b}=\frac{K_{i}}{t_{i}}$

The edge heat loss coefficient is given below:

$U_{e}=\frac{(W+L) \times L_{1} \times K_{i}}{W \times L \times t_{e}}$

An initial for the mean absorber plate temperature $T_{p}$ is made by using the approximation

$T_{p}=T_{a}=T_{i}$

The top loss coefficient $U_{t}$ can be computed by using the relation proposed by [24]

$$
\begin{aligned}
U_{t} & =\left[\frac{N}{\left.\frac{C_{t}}{T_{p}}\left(\frac{T_{P}-T_{a}}{N+f_{t}}\right)^{0.33}+\frac{1}{h_{w}}\right]^{-1}+}\right. \\
& {\left[\frac{\sigma\left(T_{p}^{2}+T_{a}^{2}\right)\left(T_{p}-T_{a}\right)}{\frac{1}{(\varepsilon p+0.05 \times N(1-\varepsilon p))}+\frac{2 \times N+f_{t}-1}{\varepsilon_{g}}-N}\right] }
\end{aligned}
$$

Where

$$
\begin{aligned}
& h_{w}=5.7+3.8 \times V_{w} \\
& C_{t}=365.9\left[1-0.00883 \times S+0.0001298 \times S^{2}\right] \\
& f_{t}=\left(1+0.04 \times h_{w}+0.0005 \times h_{w}{ }^{2}\right)(1=0.091 \times N)
\end{aligned}
$$

The overall heat loss coefficient is calculated as;

$U_{L}=\left(U_{b}+U_{e}+U_{t}\right)$

The useful heat gain is calculated as:

$Q_{u 1}=\left[I(\Gamma \alpha)-U_{L}\left(T_{p}-T_{a}\right)\right] \times A_{p}$

The mass flow rate is calculated as:

$\dot{m}=\frac{Q_{u 1}}{C_{p} \times \Delta T}$

The Reynolds number for the flow of air in the duct is computed as:

$R_{e}=\frac{G o \times D}{\mu}$

Where

$G_{O}=\frac{\dot{m}}{W \times H}$

The Nusselt number calculated using the correlations given in Table 1.

The convective heat transfer coefficient is calculated as:

$h=\frac{N_{u} \times K}{D}$

The collector efficiency factor is then determined as:

$F_{p}=\frac{h}{h+u_{L}}$

The heat removal factor is calculated as: 
$F_{o}=\frac{\dot{m} \times C_{p}}{A_{p} \times U_{L}}\left[1-\exp \left(-\frac{A_{p} U_{L} F_{p}}{\dot{m} C_{p}}\right)\right]$

The useful heat gain is computed as:

$Q_{u 2}=F_{o} \times A_{p}\left[I(\Gamma \alpha)-U_{L}\left(T_{o}-T_{i}\right)\right]$

The value of $Q_{u 1}$ and $Q_{u 2}$ are compared. Ideally the two values should be same. If the difference is more than the $0.1 \%$ of $Q_{u 1}$, then plate temperature is modified as:

$T_{p}=T_{a}+\left[\{I(\Gamma \alpha)\}-\frac{Q_{u 2}}{A_{p}} / U_{L}\right]$
Using the new plate temperature, the calculation from Eq. 30 to Eq. 42 are performed again till the difference between the two values of useful heat gain i.e. $Q_{u 1}$ and $Q_{u 2}$ is reduced to a value below $0.1 \%$ of $Q_{u 1}$.

The thermal efficiency is given as:

$$
\eta_{t h}=\frac{Q_{u 1}}{I \times A_{p}}
$$

The friction factor is calculated from the correlations given in Table 1.

The pressure drop in the duct is computed as:

Table 1: Correlations Used for Heat Transfer Coefficient and Friction Factor for Different Roughness Geometries

\begin{tabular}{|c|c|c|c|}
\hline Investigators & Types of roughness & $\begin{array}{l}\text { Range of operating } \\
\text { parameters }\end{array}$ & Correlation for Friction factor and Nusselts number \\
\hline Jaurker (2006) & Rib-groove & $\begin{array}{l}\mathrm{p} / \mathrm{e}=4.5 \text { to } 10 \\
\mathrm{e} / \mathrm{D}=0.0181 \text { to } 0.0363 \\
\mathrm{~g} / \mathrm{p}=0.3 \text { to } 0.7 \\
\mathrm{Re}=3000 \text { to } 21000\end{array}$ & $\begin{array}{l}f_{r}=0.001227(\operatorname{Re})^{-0.199}(e / D)^{0.585}(p / e)^{7.19}(g / p)^{0.645} \\
\times\left[\operatorname{Exp}\left\{-1.854(\ln (p / e))^{2}\right\}\right] \\
\times\left[\operatorname{Exp}\left\{1.513(\ln (g / p))^{2}+0.8662(\ln (g / p))^{3}\right\}\right] \\
N u_{r}=0.002062(\operatorname{Re})^{0.936}(e / D)^{0.349}(p / e)^{3.318} \\
\times\left[\operatorname{Exp}\left\{-0.868(\ln (p / e))^{2}\right\}\right] \times(g / p)^{1.108} \\
\times\left[\operatorname{Exp}\left\{2.486(\ln (g / p))^{2}+1.406(\ln (g / p))^{3}\right\}\right]\end{array}$ \\
\hline Layek (2007a) & Chamfered rib-groove & $\begin{array}{l}\mathrm{p} / \mathrm{e}=4.5 \text { to } 10 \\
\mathrm{e} / \mathrm{D}=0.022 \text { to } 0.04 \\
\mathrm{~g} / \mathrm{p}=0.3 \text { to } 0.6 \\
\phi=5^{0} \text { to } 30^{\circ} \\
\mathrm{Re}=3000 \text { to } 21000\end{array}$ & $\begin{array}{l}f_{r}=0.00245(\operatorname{Re})^{-0.124}(e / D)^{0.365}(p / e)^{4.32}(g / p)^{-1.124} \\
\times[\operatorname{Exp}(0.005 \varphi)] \times\left[\operatorname{Exp}\left\{-1.09(\ln (p / e))^{2}\right\}\right] \\
\times\left[\operatorname{Exp}\left\{-0.68(\ln (g / p))^{2}\right\}\right] \\
N u_{r}=0.00225(\operatorname{Re})^{0.92}(e / D)^{0.52}(p / e)^{1.72}(g / p)^{-1.21}(\varphi)^{1.24} \\
\times\left[\operatorname{Exp}\left\{-0.22(\ln \varphi)^{2}\right\}\right]\left[\operatorname{Exp}\left\{-0.46(\ln (p / e))^{2}\right\}\right] \\
\times\left[\operatorname{Exp}\left\{-0.74(\ln (g / p))^{2}\right\}\right]\end{array}$ \\
\hline $\begin{array}{l}\text { Momin et al. } \\
\text { (2002) }\end{array}$ & $\begin{array}{l}\mathrm{V} \text {-shaped rib } \\
\text { roughness }\end{array}$ & $\begin{array}{l}P / e=10 \\
e / D=0.02 \text { to } 0.034 \\
\alpha=30^{\circ} \text { to } 90^{\circ} \\
\operatorname{Re}=2500 \text { to } 18,000\end{array}$ & $\begin{array}{l}f_{r}=6.266 \times(\operatorname{Re})^{-0.425}(e / D)^{0.565}\left(\alpha / 60^{0}\right)^{-0.093} \\
\times \operatorname{Exp}\left[-0.719 \times\left(\ln \alpha / 60^{0}\right)^{2}\right] \\
N u_{r}=0.067 \times(\operatorname{Re})^{0.888}(e / D)^{0.424}\left(\alpha / 60^{0}\right)^{-0.077} \\
\times \operatorname{Exp}\left[-0.782 \times\left(\ln \alpha / 60^{0}\right)^{2}\right]\end{array}$ \\
\hline $\begin{array}{l}\text { Saini \& Verma } \\
(2008)\end{array}$ & $\begin{array}{l}\text { Dimple-shape } \\
\text { roughness }\end{array}$ & $\begin{array}{l}\mathrm{P} / \mathrm{e}=8 \text { to } 12 \\
\mathrm{e} / \mathrm{D}=0.0189 \text { to } 0.038 \\
\mathrm{Re}=2000 \text { to } 12000\end{array}$ & $\begin{array}{l}f_{r}=0.642(\operatorname{Re})^{-0.423}(P / e)^{-0.465}\left[\exp (0.054)(\log (P / e))^{2}\right] \\
\times(e / D)^{-0.0214}\left[\exp (0.840)(\log (e / D))^{2}\right] \\
N u_{r}=5.2 \times 10^{-4}(\operatorname{Re})^{3.15} \times(e / D)^{0.033} \\
\times\left[\exp (-2.12)(\log (P / e))^{2}\right] \times\left[\exp (-1.30)(\log (e / D))^{2}\right]\end{array}$ \\
\hline
\end{tabular}


$\Delta P=\frac{4 f L V^{2}}{2 D}$

$P=\frac{\dot{m} \times \Delta P}{\rho}$

$\Delta T_{m}=T_{p}-T_{f}$

\section{RESULTS AND DISCUSSION}

The procedure describe in articles 2 and 4 has been used to calculate the effective efficiency, entropy, irreversibility distribution ration and entropy generation number of solar air heater ducts having different types of artificial roughness as given in Table 1. These calculations have been carried out for a set of operating parameters as given in Table 2 . The discussion for different types of roughness is given below:

Table 2: Typical Values of System and Operating Parameters

\begin{tabular}{|c|c|}
\hline Parameters & Values \\
\hline \hline Length, $\mathrm{L}$ & $1000 \mathrm{~mm}$ \\
\hline Width, $\mathrm{W}$ & $160 \mathrm{~mm}$ \\
\hline Height, $\mathrm{H}$ & $22 \mathrm{~mm}$ \\
\hline Insolation, I & $1000 \mathrm{~W} / \mathrm{m}^{2}$ \\
\hline Transmittance-absorptance, $\Gamma \alpha$ & 0.8 \\
\hline Emittance of glass, $\epsilon_{g}$ & 0.88 \\
\hline Emittance of plate, $\epsilon_{p}$ & 0.9 \\
\hline Temperature rise parameter, $\frac{\Delta T}{I}$ & $0.002-0.026 \mathrm{Km}{ }^{2} / \mathrm{W}$ \\
\hline Relative roughness pitch, $\mathrm{p} / \mathrm{e}$ & 10 \\
\hline Relative roughness height, e/D & $0.022-0.04$ \\
\hline Groove position to pitch ratio, $\mathrm{g} / \mathrm{P}$ & 0.4 \\
\hline Chamfer angle, $\phi$ & $18^{\circ}$ \\
\hline Angle of attack of flow, $\alpha$ & $60^{\circ}$ \\
\hline
\end{tabular}

\subsection{Rib-Grooved Artificial Roughness}

Figure 2 depicts that the effective efficiency increases with an increase of temperature rise parameter, then attains a maximum value and then again decreases on further increase in temperature rise parameter. It has also been seen that for a value of temperature rise parameter lower than 0.006, the maximum values of effective efficiency are observed for relative roughness height of 0.022 , while the relative roughness height of 0.04 results in minimum value of effective efficiency. This trend is reversed for the temperature rise parameter higher than 0.006 . It may be due to that maximum heat transfer and minimum pressure drop occur for temperature rise parameter below 0.006 for relative roughness height of 0.002 and above 0.006 for relative roughness height of 0.04 . The maximum value of effective efficiency may correspond to relative roughness height of 0.04 and temperature rise parameter values between 0.0075 and 0.0085 .

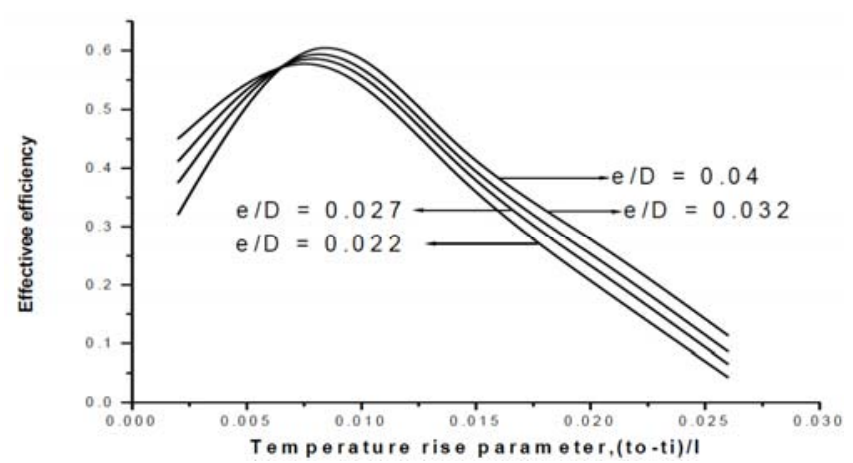

Figure 2: Effective efficiency vs. temperature rise parameter for rib-grooved roughness.

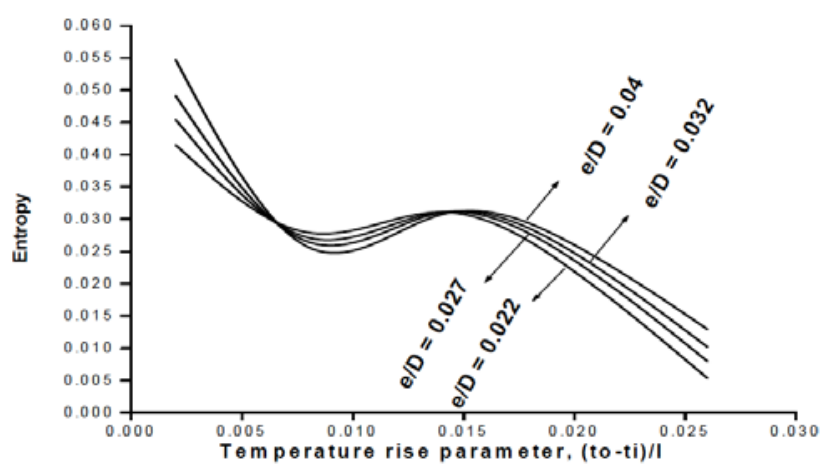

Figure 3: Entropy vs. temperature rise parameter for rib-grooved roughness.

Figure 3 depicts the effect of relative roughness height on entropy with temperature rise parameter. It has been seen that entropy decreases with increase in temperature rise parameter, attains a minimum value and then increases on further increase in temperature rise parameters and further decreases with increase in temperature rise parameter. It has also been observed that for a value of temperature rise parameter lower than about 0.006, the minimum value of entropy obtained for relative roughness height of 0.022 , while the relative roughness height of 0.04 results in maximum value of entropy. This trend is reversed for the temperature rise parameters between 0.006 and 0.014 . Trend is again changed beyond temperature rise parameter 0.014 . The minimum value of entropy may correspond to relative roughness height of 0.04 and temperature rise parameter values between 
0.0075 and 0.0085 . It may be due to that irreversibility caused by heat transfer across the wall fluid temperature difference and fluid friction are minimum for temperature rise parameter between 0.0075 and 0.0085 . Beyond temperature rise parameter value of 0.014 , the minimum value may correspond to relative roughness height of 0.022 .

Figure 4 depicts that for a value of temperature rise parameter lower than 0.0085 , the maximum values of irreversibility distribution ratio are observed for the relative roughness height of 0.04 , while the relative roughness height of 0.022 results in minimum value of irreversibility distribution ratio. Beyond temperature rise parameters 0.0085 , the value of irreversibility distribution ratio is very less and approximately same irrespective of different relative roughness height.

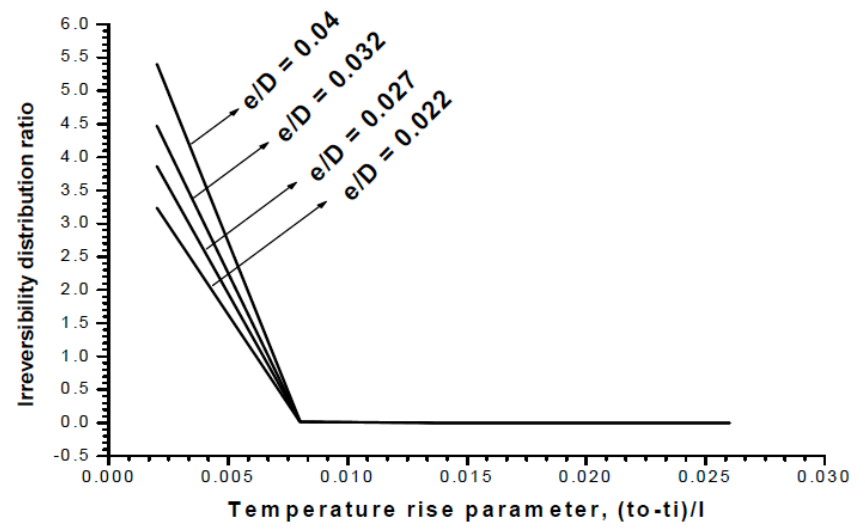

Figure 4: Irreversibility distribution ratio vs. temperature rise parameter for rib-grooved roughness.

Figure 5 depicts that the entropy generation number decreases with an increase in temperature rise parameter, attains a minimum value and then increases for further increase in temperature rise parameter. The minimum value of entropy generation number may correspond to relative roughness height of 0.04 and temperature rise parameter value between 0.0075 and 0.0085 .

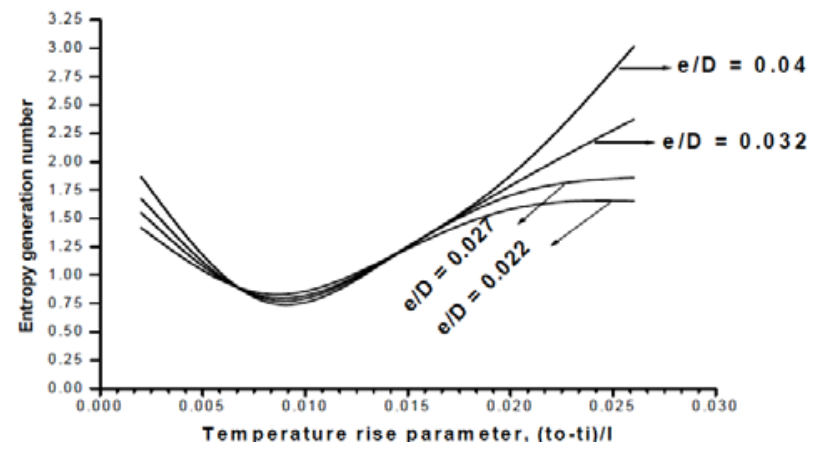

Figure 5: Entropy generation number vs. temperature rise parameter for rib-grooved roughness.

\subsection{Chamfered Rib-Grooved Artificial Roughness}

Figure 6 depicts that for a value of temperature rise parameter lower than about 0.006, the maximum values of effective efficiency are observed for relative roughness height of 0.022 , while the relative roughness height of 0.04 results in minimum value of effective efficiency. This trend is reversed for the temperature rise parameter higher than about 0.006 . The maximum values of effective efficiency may correspond between 0.0082 and 0.0087 for relative roughness heights vary from 0.022 to 0.04 .

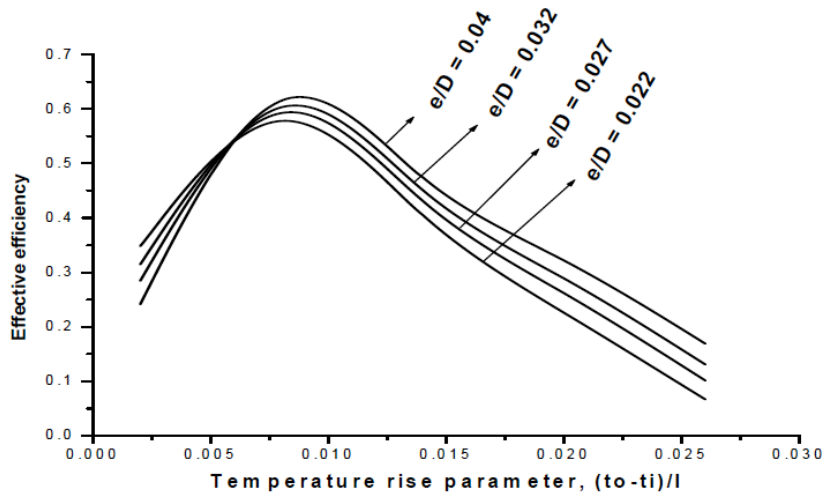

Figure 6: Effective efficiency vs. temperature rise parameter for the chamfered rib-grooved roughness.

Figure 7 depicts that for a value of temperature rise parameter lower than about 0.006 , the maximum value of entropy is obtained for relative roughness height of 0.04 . The minimum value of entropy is obtained between values of temperature rise parameter of 0.009 to 0.0095 . Beyond temperature rise parameter 0.016 , the minimum value may correspond to relative roughness height of 0.022 .

Figure $\mathbf{8}$ depicts that for a value of temperature rise parameter lower than 0.0078 , the maximum value of irreversibility distribution ratio is very less and approximately same irrespective of different values of relative roughness height.

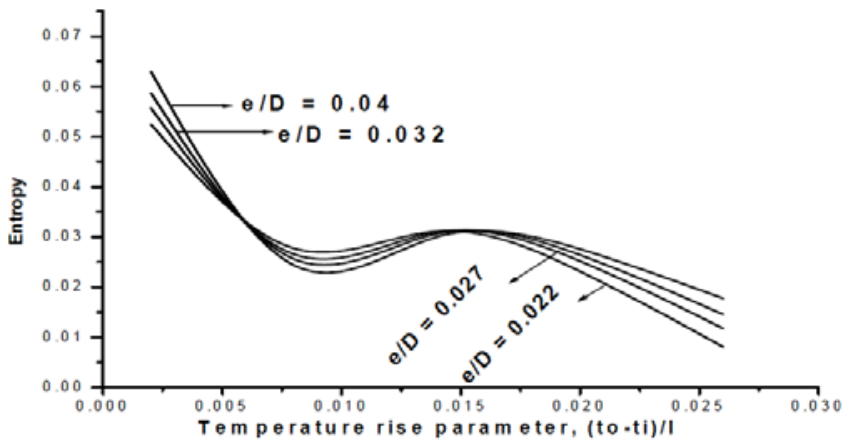

Figure 7: Entropy vs. temperature rise parameter for the chamfered rib-grooved roughness. 


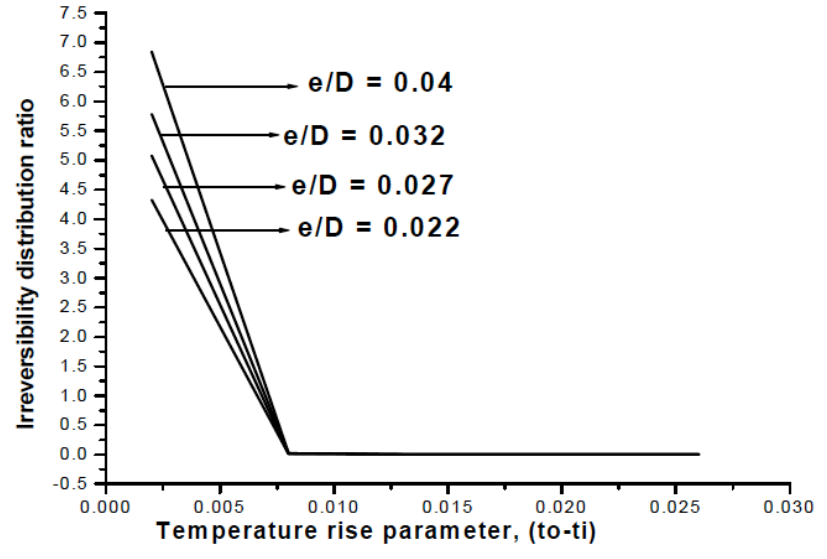

Figure 8: Irreversibility distribution ratio vs. temperature rise parameter for the chamfered rib-grooved roughness.

Figure 9 depicts that minimum value of entropy generation number lies for temperature rise parameter between 0.006 and 0.008 .

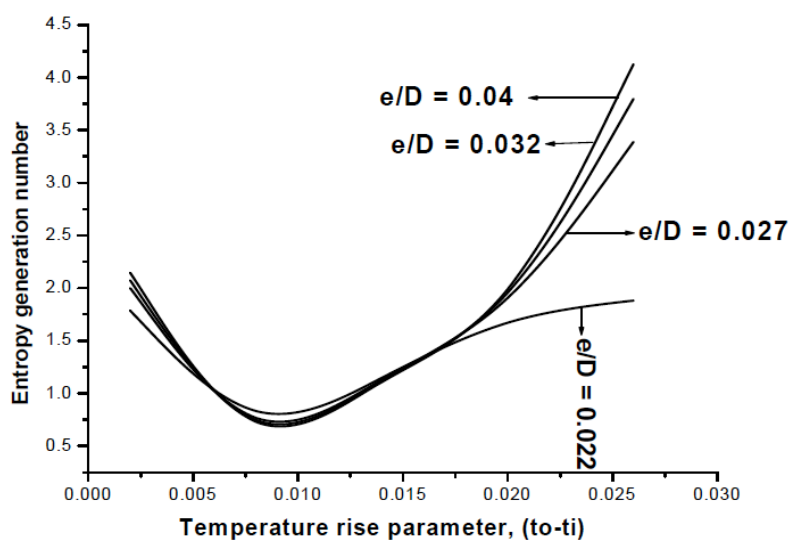

Figure 9: Entropy generation number vs. temperature rise parameter for the chamfered rib-grooved roughness.

\section{CONCLUSIONS}

The present analysis is undertaken with the objective of detailed study of effect of different artificial roughness on effective efficiency, entropy, irreversibility distribution ratio and entropy generation number. It has been observed that entropy generation is minimum, where effective efficiency is maximum, which satisfied the Second law of thermodynamics. Solar air heater having dimple-shape roughness elements is found to have better effective efficiency with minimum entropy and entropy generation number.

\section{REFERENCES}

[1] Close DJ. Solar air heaters for low and moderate temperature application. Solar Energy 1963; 7: 117-24. http://dx.doi.org/10.1016/0038-092X(63)90037-9

[2] Laohalertdecha S, Naphon P, Wongwises S. A review of electrohydrodynamic enhancement of heat transfer. Renew Sustainable Energy Rev 2007; 11: 858-76. http://dx.doi.org/10.1016/j.rser.2005.07.002
[3]

[4]
Han JC, Glicksman LR, Rohsenow WM. An investigation of heat transfer and friction for rib-roughened surfaces. Int $\mathrm{J}$ Heat Mass Transfer 1978; 21: 1143-56. http://dx.doi.org/10.1016/0017-9310(78)90113-8

Han JC, Park JS, Lei CK. Heat transfer enhancement in channel with turbulence promoters. J Eng Gas Turbine Power 1985; 107: 628-35.

http://dx.doi.org/10.1115/1.3239782

Han JC, Zhang YM. High performance heat transfer ducts with parallel broken and V-shaped broken ribs. Int $\mathrm{J}$ Heat Mass Transfer 1992; 35: 513-23. http://dx.doi.org/10.1016/0017-9310(92)90286-2

Lau SC, McMillin RD, Han JC. Turbulent heat transfer and friction in a square channel with discrete rib and turbulators. $J$ Turbomachinery 1991; 113: 360-66. http://dx.doi.org/10.1115/1.2927884

Lau SC, McMillin RD, Han JC. Heat transfer characteristics of turbulent flow in a square channel with angled discrete ribs. J Turbomachinery 1991; 113: 367-74.

http://dx.doi.org/10.1115/1.2927885

Hwang J, Liou T. Heat transfer and friction in a low-aspectratio rectangular channel with staggered slit-ribbed walls. Int J Rotating Machin 1998; 4: 283-91. http://dx.doi.org/10.1155/S1023621X98000244

Prasad BN, Saini JS. Effect of artificial roughness on heat transfer and friction factor in a solar air heater. Solar Energy 1980; 41: 555-60. http://dx.doi.org/10.1016/0038-092X(88)90058-8

Gupta D, Solanki SC, Saini JS. Heat and fluid flow in rectangular solar air heater ducts having transverse rib roughness on absorber plates. Solar Energy 1993; 51: 31-37. http://dx.doi.org/10.1016/0038-092X(93)90039-Q

Saini RP, Saini JS. Heat transfer and friction factor correlations for artificially roughened duct with expanded metal mesh as roughness element. Int $\mathrm{J}$ Heat Mass Transfer 1997; 40: 973-86.

http://dx.doi.org/10.1016/0017-9310(96)00019-1

Karwa R, Solanki SC, Saini JS. Heat transfer co-efficient and friction factor correlations for the transitional flow regime in rib-roughened rectangular ducts. Int $\mathrm{J}$ Heat Mass Transfer 1999; 42: 1597-15

\section{http://dx.doi.org/10.1016/S0017-9310(98)00252-X}

Bhagoria JL, Saini JS, Solanki SC. Heat transfer coefficient and friction factor correlations for rectangular solar air heater duct having transverse wedge shaped rib roughness on the absorber plate. Renewable Energy 2002; 25: 341-69. http://dx.doi.org/10.1016/S0960-1481(01)00057-X

Aharwal KR, Gandhi BK, Saini JS. Experimental investigation of heat transfer enhancement due to a gap in an inclined continuous rib arrangement in a rectangular duct of solar air heater. Renewable Energy 2008; 33: 585-96. http://dx.doi.org/10.1016/j.renene.2007.03.023

] Jaurker AR, Saini JS, Gandhi BK. Heat transfer and friction characteristics of rectangular solar air heater duct using ribgrooved artificial roughness. Solar Energy 2006; 80: 895907.

http://dx.doi.org/10.1016/j.solener.2005.08.006

Karmare SV, Tikekar AN. Heat transfer and friction factor correlation for artificially roughened duct with metal grit ribs. Int J Heat Mass Transfer 2007; 50: 4342-51.

http://dx.doi.org/10.1016/j.ijheatmasstransfer.2007.01.065

Layek A, Saini JS, Solanki SC. Heat transfer and friction characteristics for artificially roughened ducts with compound turbulators. Int J Heat Mass Transfer 2007; 50: 4845-54. http://dx.doi.org/10.1016/j.ijheatmasstransfer.2007.02.042

Layek A, Saini JS, Solanki SC. Second law optimization of a solar air heater having chamfered rib-groove roughness on absorber plate. Renewable Energy 2007; 32: 1967-80. http://dx.doi.org/10.1016/j.renene.2006.11.005 
[19] Varun, Saini RP, Singal SK. Investigation of thermal performance of solar air heater having roughness elements as a combination of inclined and transverse ribs on the absorber plate. Renewable Energy 2008; 33: 1398-405. http://dx.doi.org/10.1016/j.renene.2007.07.013

[20] Saini RP, Verma J. Heat transfer and friction factor correlations for a duct having dimple-shape artificial roughness for solar air heater. Energy 2008; 33: 1277-87. http://dx.doi.org/10.1016/j.energy.2008.02.017

[21] Momin A-ME, Saini JS, Solanki SC. Heat transfer and friction in solar air heater duct with V-shaped rib roughness on absorber plate. Int J Heat Mass Transfer 2002; 45: 3383-96. http://dx.doi.org/10.1016/S0017-9310(02)00046-7
[22] Bejan A. Entropy generation through heat and fluid flow. New York: Wiley-Interscience Publication 1982.

[23] Cortes A, Piacentini R. Improvement of the efficiency of a bare solar collector by means of turbulence promoters. Appl Energy 1990; 36: 253-56.

http://dx.doi.org/10.1016/0306-2619(90)90001-T

[24] Klien SA. Calculation of flat plate loss coefficients. Solar Energy 1975; 17: 79-80.

http://dx.doi.org/10.1016/0038-092X(75)90020-1 